\title{
The efficacy of pregabalin for the management of acute and chronic postoperative pain in thoracotomy: a meta-analysis with trial sequential analysis of randomized-controlled trials
}

This article was published in the following Dove Medical Press journal:

Journal of Pain Research

Yijin Yu'

Nan Liu ${ }^{2}$

Qingxin Zeng ${ }^{3}$

Jing Duan'

Qi Bao'

Min Lei'

Jinning Zhao'

Junran $X_{i e}$

'Department of Anesthesiology, Sir Run Run Shaw Hospital, School of Medicine, Zhejiang University, Zhejiang, China; ${ }^{2}$ Department of Anesthesiology, Hangzhou Xiasha Hospital, Zhejiang, China; ${ }^{3}$ Department of Thoracic Surgery, Sir Run Run Shaw Hospital, School of Medicine, Zhejiang University, Zhejiang, China
Correspondence: Junran Xie

Department of Anesthesiology, Sir Run Run Shaw Hospital, School of Medicine, Zhejiang University, 3 Qingchun Road East, Jianggan District, Hangzhou 310016 ,

Zhejiang, China

Tel +86 I38 58I262I6

Email xiejunran@zju.edu.cn
Purpose: Pregabalin is commonly used as an analgesic for neuropathic pain. But pregabalin as an adjunct to a multimodal analgesic regimen - although standard clinical protocol in some settings - has remained controversial. This meta-analysis was conducted to identify the efficacy of pregabalin for management of postoperative pain in thoracotomy.

Materials and methods: Pubmed, Embase, Cochrane, Web of Science, Springer, and Clinical Trial Register database were searched for randomized controlled trials (RCTs) of pregabalin in preventing postoperative pain in thoracotomy. Review Manager 5.3 and STATA 12.0 were selected to conduct the meta-analysis. Trial sequential analysis was used to control random errors and calculate the required information size.

Results: Nine RCTs with 684 patients were included in our meta-analysis. Outcomes favoring pregabalin included less pain on a $0-10$ scale on 1 day [mean difference (MD): -0.87 ; 95\% CI: -1.55 to $-0.19 ; P=0.01$ ], 3 days (MD: $-1.55 ; 95 \%$ CI: -1.93 to $-1.18 ; P<0.00001$ ), 1 month (MD: -1.58 ; $95 \%$ CI: -2.75 to $-0.42 ; P=0.008$ ), 3 months (MD: -1.69 ; $95 \%$ CI: -2.71 to $-0.66 ; P=0.001)$ postoperatively, and less incidence of neuropathic pain (OR: $0.20 ; 95 \% \mathrm{CI}$ : 0.05-0.91; $P=0.04$ ), less mean morphine consumption (MD: $-5.03 ; 95 \% \mathrm{CI}$ : -8.06 to -1.99 ; $P=0.001$ ), but more dizziness (OR: $3.33 ; 95 \%$ CI: $1.36-8.17 ; P=0.009)$, more drowsiness (OR: 8.61; 95\% CI: $2.23-33.20 ; P=0.002$ ), and less constipation (OR: 0.23 ; 95\% CI: $0.09-0.59$; $P=0.002)$. There was no statistical differences in pain score on 7 days (MD:- $0.77 ; 95 \% \mathrm{CI}$ : -2.38 to $0.84 ; P=0.35$ ), nausea (OR: $0.73 ; 95 \% \mathrm{CI}: 0.42-1.26 ; P=0.26$ ), and vomiting (OR: $0.83 ; 95 \%$ CI: $0.36-1.90 ; P=0.65)$.

Conclusion: Pregabalin can prevent postoperative pain in thoracotomy and decrease incidence of neuropathic pain and morphine consumption. Pregabalin may be a valuable asset in management of acute and persistent postoperative pain in thoracotomy.

Keywords: pregabalin, postoperative pain, thoracotomy, meta-analysis, neuropathic pain

\section{Introduction}

Patients commonly experience acute to chronic pain after thoracotomy. Bayman et $\mathrm{al}^{1}$ reported that a higher severity of pain at first postoperative 3 days may develop a higher rate of persistent pain. The incidence of chronic pain was $27 \%$ in thoracotomy and $8.2 \%$ were limited in their daily life. The incidence of chronic pain in video-assisted thoracoscopic surgery (VATS) was still not lower. Homma et $\mathrm{al}^{2}$ reported that incidence of chronic neuropathic pain was $25.9 \%$ in VATS, and $18.8 \%$ even in a year later. 
Thoracic epidural analgesia remained a controversy due to complications related to the catheterization procedure. ${ }^{3}$ Opioid-based patient-controlled analgesia has been widely used for its analgesic efficacy but with several adverse effects including respiratory depression, sedation, vomiting, and physical dependence, and it may not be effective for chronic neuropathic pain. ${ }^{4,5}$

Pregabalin is a structural analog of $\gamma$-aminobutyric acid that acts on the $\alpha 2 \delta$ subunit of voltage-dependent calcium channels, which can reduce the release of neurotransmitters. ${ }^{6}$ It has been commonly used in treatment for neuropathic pain, but has remained a controversy in alleviating postoperative pain. ${ }^{7}$ There was no systematic review with direct-evidence meta-analysis of randomized-controlled trials (RCTs) for pregabalin used in postoperative pain of thoracotomy. This meta-analysis was sought to determine whether pregabalin used systematically can reduce postoperative pain.

\section{Material and methods}

The protocol for the meta-analysis is registered with PROSPERO (CRD42018100634).

\section{Search strategy}

This systematic review of RCTs was performed in accordance with the criteria of the PRISMA statement and the current recommendations of the Cochrane Collaboration. ${ }^{8,9}$ We searched the PubMed, Embase, Cochrane, Web of Science, Springer, and Clinical trials register databases for related articles published on or before April 30, 2018, using the terms “ thoracotomy pain" or "thoracoscopic pain" and "pregabalin".

\section{Study selection}

\section{Inclusion criteria}

1. Settings and design: RCTs of pregabalin for prevention of postoperative pain in thoracotomy.

2. Study subjects: Patients who suffered postoperative pain in thoracotomy.

3. Interventions: The experimental group was administered pregabalin orally; the control group was administered conventional analgesia or placebo.

4. Outcome indicators: Postoperative pain scores and incidence of neuropathic pain.

\section{Exclusion criteria}

1. Combination with other antiepileptic drugs or anticonvulsive drugs.

2. Incomplete data.

\section{Trial selection, data extraction, and quality assessment}

Two authors (Y-JY and NL) separately screened the articles, extracted data based on the inclusion and exclusion criteria, and evaluated the quality of each RCT using Cochrane Collaboration Risk of Bias Tool. ${ }^{10}$ Disagreements were resolved by consensus. The opinion of a third author (J-RX) was obtained when agreement could not be reached.

The extracted data included first author's name, publication data, type of surgery and anesthesia, patient demographic, sample size, details regarding pregabalin medication (dose and duration), morphine consumption, pain scores, postoperative complications, and side effects (nausea, vomiting, dizziness, drowsiness, and constipation).

RCTs were assessed for various types of bias, including selection, performance, detection, attrition, and reporting. RCT quality scores were not a factor for trial exclusion.

\section{Definitions and outcomes}

The main outcomes included the numerical rating scale or the visual analog scale (VAS) pain scores, the incidence of neuropathic pain, mean morphine consumption, and incidence of nausea, vomiting, dizziness, drowsiness, and constipation postoperatively.

If studies did not show complete data, we e-mailed authors requesting the original data. If there was no reply, we use the software of plot digitizer 2.6.8.0 to measure the exact numbers in figures. Pain scores were transformed to a standardized $0-10$ analog scale $(0=$ no pain and $10=$ worst pain imaginable). ${ }^{11}$ Morphine consumption was the standard for opioid consumption. Fentanyl was converted to equi-analgesic morphine equivalent doses based on the following conversion scale: $100: 1 .^{12}$

\section{Statistical methods}

The data were analyzed by Review Manager Software 5.3. The effect size for continuous data is expressed as the mean difference and the $95 \% \mathrm{CI}$. The effect size for dichotomous data is expressed as the OR and the $95 \% \mathrm{CI}$. The $\chi^{2}$-test $P$-value and the $I^{2}$-value were used to determine the level of heterogeneity. A random effect model was used in cases of heterogeneity $\left(P<0.1\right.$ or $\left.I^{2} \geq 50 \%\right)$, and a fixed effect model was used in cases of homogeneity $\left(P \geq 0.1\right.$ or $\left.P^{2}<50 \%\right) .{ }^{13}$ Publication bias using the Egger test and sensitivity analyses was conducted by STATA 12.0 , where $P>0.05$ indicated no statistically significant publication bias. 


\section{Trial sequential analysis}

Meta-analysis can result in type I errors $(\alpha)$ owing to repetitive testing of accumulated data, especially when the included studies have small sample sizes. Thus, we used trial sequential analysis (TSA) to examine the reliability and conclusiveness of our results. TSA depends on the quantification of the required information size. We calculated a diversity-adjusted $\left(D^{2}\right.$ required information size), since the heterogeneity adjustment with $P$ underestimates the required information size and estimated the required information size using 0.05 for type 1 error and 0.20 for type 2 error. The relative risk reduction from the control group event rate from low-bias-risk trials included in the meta-analysis, according to the TSA user manual. ${ }^{14}$ TSA software version 0.9.5.10 Beta (http://www.ctu.dk/tsa) was used in this study. If the cumulative $Z$-curve crossed the trial sequential monitoring boundary or exceeded the required information size, a significant result had been reached and no further studies were needed. Otherwise, further studies were necessary to confirm the results.

\section{Results}

\section{Study selection and characteristics}

The literature search included 9 qualifying RCTs with 684 patients that met inclusion criteria (Figure 1). ${ }^{15-23}$ Quality assessment of RCTs was presented in Figures 2 and 3. The characteristics of patients and interventions are presented in Table 1. One was conducted in multicenters, ${ }^{15}$ and others were conducted in a single center. All RCTs applied randomized strategies. Three studies applied double-blind strategies. Three hundred forty-four patients were in the pregabalin group and 340 were in the control group. ${ }^{15,20,21}$ Two different dosages of pregabalin $150 \mathrm{mg}^{16-19,21,22}$ or 300 $\mathrm{mg}^{15,20,23}$ were administered to patients orally every day. The administration period was from 1 to 90 days. Postoperative analgesia included epidural analgesia, celecoxib, morphine, and nonsteroidal anti-inflammatory drugs. Postoperative analgesia details in control group can be seen in Table 1.

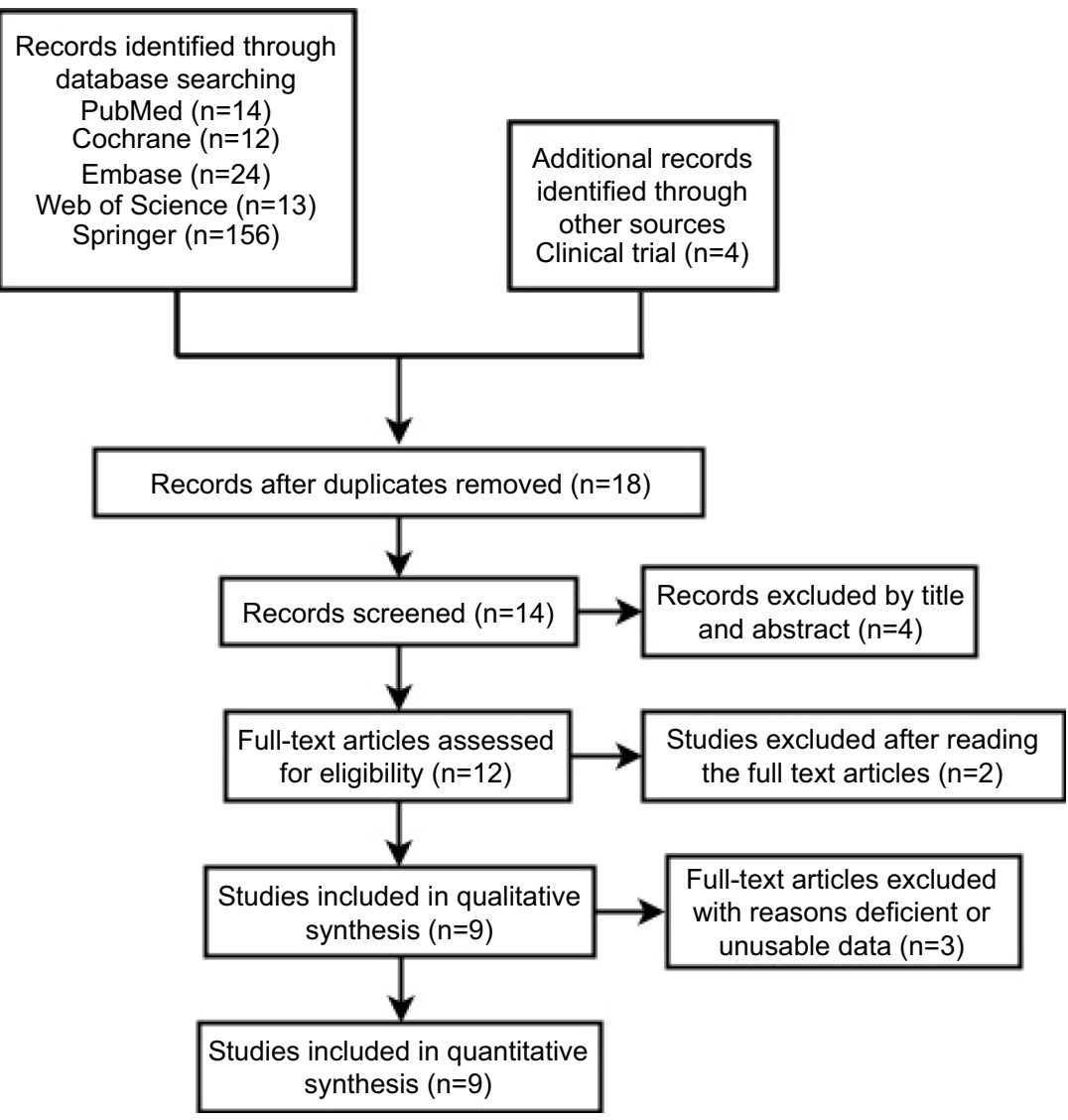

Figure I Search results and selection procedure. 


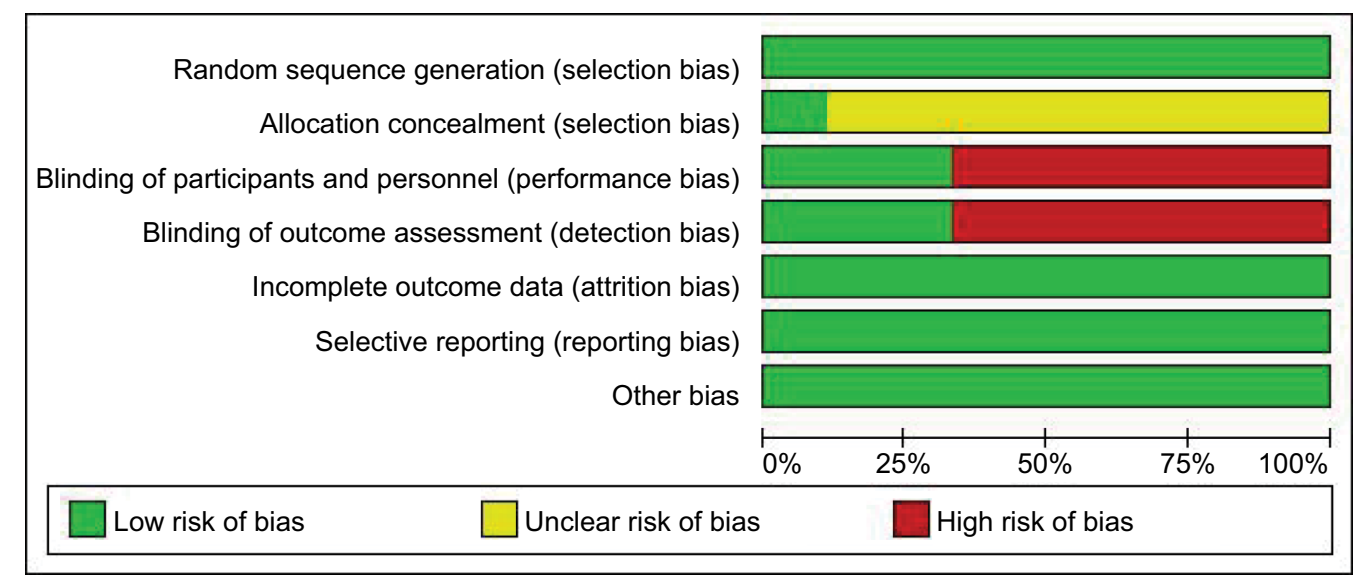

Figure 2 Risk of bias graph.

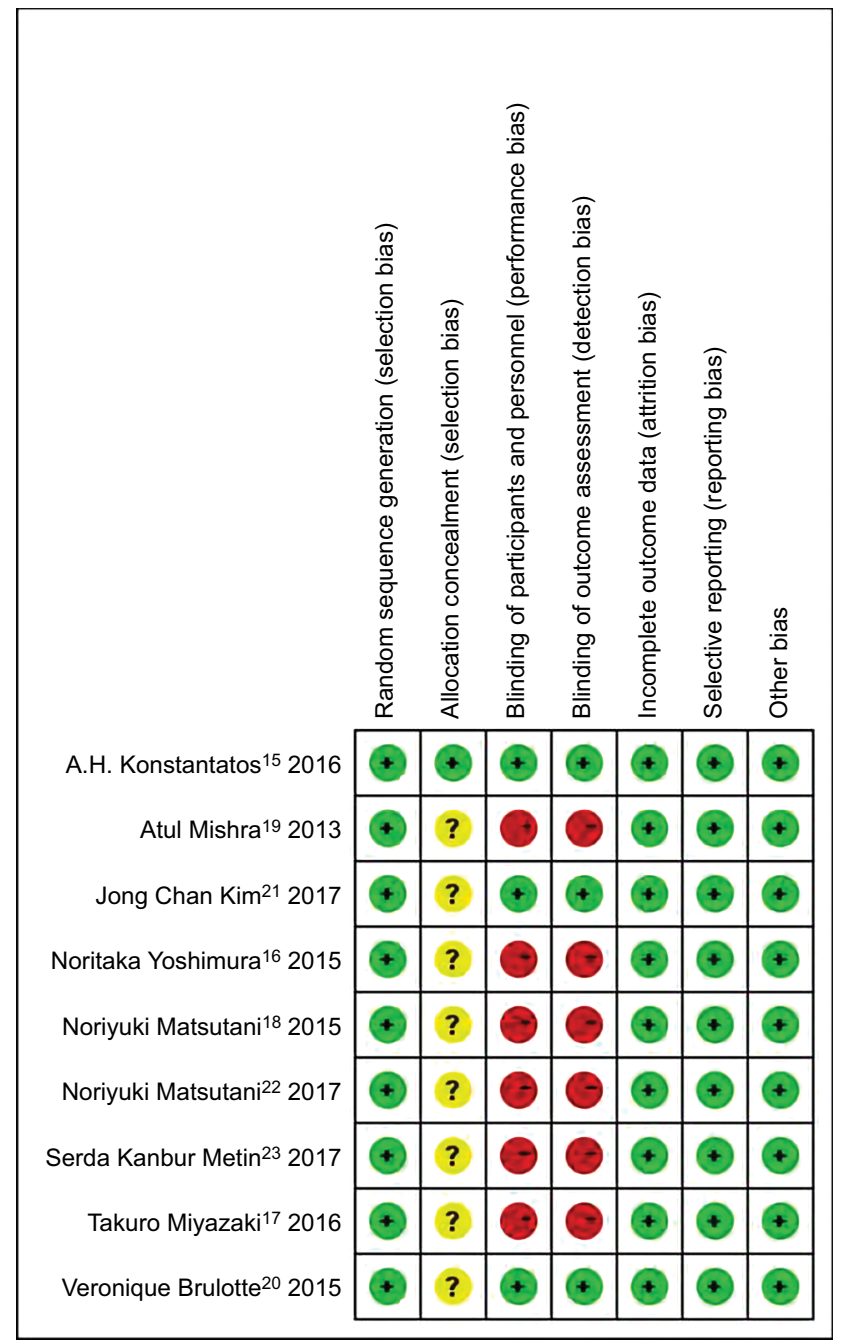

Figure 3 Risk of bias summary.

\section{Meta-analysis results Postoperative pain scores}

Six studies reported pain scores on postoperative 1 day. Pregabalin reduced scores by 0.87 points $(\mathrm{n}=385 ; 95 \% \mathrm{CI}$, -1.55 to $-0.19, I^{2}=63 \%, P=0.01$ ). Four studies reported on postoperative 3 days. Pregabalin reduced scores by 1.55 points (n=275; $95 \% \mathrm{CI},-1.93$ to $-1.18, I^{2}=0 \%, P<0.00001$ ). Two studies reported on postoperative 1 month. Pregabalin reduced scores by 1.58 points $(\mathrm{n}=135 ; 95 \% \mathrm{CI},-2.75$ to $-0.42, I^{2}=58 \%, P=0.008$ ). Four studies reported on postoperative 3 months. Pregabalin reduced scores by 1.69 points ( $\mathrm{n}=235 ; 95 \% \mathrm{CI},-2.71$ to $-0.66, I^{2}=83 \%, P=0.001$ ). There was no difference on postoperative 7 days $(\mathrm{n}=184 ; 95 \% \mathrm{CI}$ : $-2.38-0.84 ; I^{2}=92 \% ; P=0.35$; Figure 4 ).

The Egger test for publication bias $(P=0.601$ on postoperative 1 day; $P=0.778$ on postoperative 3 days; $P=0.761$ on postoperative 7 days; and $P=0.167$ on postoperative 3 months); and sensitivity analysis did not significantly alter the summarized results. TSA results demonstrated that the cumulative $Z$-score of VAS on 1 day, 3 days, 1 month, and 3 months crossed its monitoring boundaries and reliable conclusions had been drawn. But the sample size of VAS on 7 days did not reach the required sample size (Figure 5).

\section{Incidence of neuropathic pain postoperatively}

Three studies ( $\mathrm{n}=217)$ investigated the incidence of postoperative neuropathic pain. The incidence of neuropathic pain was $80 \%$ lower with pregabalin $\left(95 \% \mathrm{CI}, 0.05-0.91, I^{2}=62 \%\right.$, $P=0.04)$. The Egger test for publication bias $(P=0.296)$ and sensitivity analysis did not significantly alter the summarized 
Table I Trial characteristics

\begin{tabular}{|c|c|c|c|}
\hline \multirow[t]{2}{*}{ Reference, year } & \multirow[t]{2}{*}{ Type } & Intervention & Outcomes \\
\hline & & $\begin{array}{l}\text { Pregabalin and control group }(s)(n) \text {, dose } \\
\text { and administration }\end{array}$ & Pain scoring system follow-up time \\
\hline $\begin{array}{l}\text { Konstantatos et al, } \\
2016^{15}\end{array}$ & $\begin{array}{l}\text { Multicenter } \\
\text { RCT } \\
\text { double-blind }\end{array}$ & $\begin{array}{l}\text { Pregabalin I } 50 \mathrm{mg}(52) \text {, placebo (48), orally } 150 \\
\text { mg } 30 \text { minutes before surgery and I50 mg twice } \\
\text { daily for } 5 \text { days postsurgery }\end{array}$ & $\begin{array}{l}\text { VAS (in the recovery room and then twice-daily } \\
\text { for } 6 \text { days) McGill Pain Questionnaire ( } 6 \text { weeks } \\
\text { and } 3,6 \text {, and } 9 \text { months) }\end{array}$ \\
\hline $\begin{array}{l}\text { Miyazaki et al, } \\
2016^{17}\end{array}$ & $\begin{array}{l}\text { Single-center } \\
\text { RCT }\end{array}$ & $\begin{array}{l}\text { Pregabalin } 75 \mathrm{mg}+\text { ropivacaine }(8 \mathrm{mg} / \mathrm{h})+ \\
\text { celecoxib } 200 \mathrm{mg}(33) \text {, ropivacaine }(8 \mathrm{mg} / \mathrm{h})+ \\
\text { celecoxib } 200 \mathrm{mg}(34) \text {, pregabalin (patients could } \\
\text { tolerate oral intake during hospitalization) and } \\
\text { celecoxib ( } \geq \text { I week) given orally b.i.d. epidural } \\
\text { ropivacaine } \leq 5 \text { days postsurgery }\end{array}$ & $\begin{array}{l}\text { NRS (prior to and every day after surgery and } \\
\text { I and } 3 \text { months after being discharged), PDQ (a } \\
\text { screening tool for neuropathic pain } 7 \text { days after } \\
\text { surgery, I and } 3 \text { months after being discharged), } \\
\text { PCS (a screening tool for pain catastrophizing } \\
\text { before surgery, } 7 \text { days after surgery, and I and } 3 \\
\text { months after discharged) }\end{array}$ \\
\hline $\begin{array}{l}\text { Yoshimura et al, } \\
2015^{16}\end{array}$ & $\begin{array}{l}\text { Single-center } \\
\text { RCT }\end{array}$ & $\begin{array}{l}\text { Pregabalin } 75 \mathrm{mg} \text { (25), acetaminophen } 400 \mathrm{~g} \\
\text { +codeine } 20 \mathrm{mg}(25) \text {, orally } 75 \mathrm{mg} \text { b.i.d. for } 3 \\
\text { days to } 2 \text { weeks postoperatively, orally } 400 \mathrm{mg} \text {, } \\
20 \mathrm{mg} \text { t.i.d. for } 3 \text { days to } 2 \text { weeks postoperatively }\end{array}$ & $\begin{array}{l}\text { VAS (I, } 2,3 \text { days and } 2,12 \text { weeks after surgery) } \\
\text { Neuropathic Pain Questionnaire ( } 12 \text { weeks after } \\
\text { being surgery) }\end{array}$ \\
\hline $\begin{array}{l}\text { Matsutani et al, } \\
2015^{18}\end{array}$ & $\begin{array}{l}\text { Single-center } \\
\text { RCT }\end{array}$ & $\begin{array}{l}\text { Pregabalin } 75 \mathrm{mg}(34) \text {, loxoprofen } 60 \mathrm{mg}(34) \text {, } \\
\text { orally } 75 \mathrm{mg} \text { b.i.d. } 2 \text { hours before operation to } \\
2 \text { weeks after operation, stopped until pain score } \\
<3 \text {, orally } 60 \mathrm{mg} \text { t.i.d. } 2 \text { hours before operation } \\
\text { to } 2 \text { weeks after operation, stopped until pain } \\
\text { score }<3\end{array}$ & $\begin{array}{l}\text { NRS (on the first, third, and seventh day, and } \\
\text { during the 4th, 8th, and I2th week after surgery). } \\
\text { LANSS (distinguish neuropathic pain from } \\
\text { nociceptive pain on the Ist, 3rd, and 7th day, and } \\
\text { during the 4th and 8th weeks after surgery) }\end{array}$ \\
\hline $\begin{array}{l}\text { Mishra et al, } \\
2013^{19}\end{array}$ & $\begin{array}{l}\text { Single-center } \\
\text { RCT }\end{array}$ & $\begin{array}{l}\text { Pregabalin I } 50 \mathrm{mg} \text { ( } 25) \text {, diclofenac sodium } 75 \mathrm{mg} \\
\text { (25), orally I50 mg qd from I hour before } \\
\text { surgery to } 2 \text { I days after surgery, orally } 75 \mathrm{mg} \\
\text { t.i.d. from I hour before surgery to } 2 \text { I days after } \\
\text { surgery }\end{array}$ & $\operatorname{VAS}(1,3,6,12$, and 24 weeks after surgery) \\
\hline $\begin{array}{l}\text { Brulotte et al, } \\
2015^{20}\end{array}$ & $\begin{array}{l}\text { Single-center } \\
\text { RCT } \\
\text { Double-blind }\end{array}$ & $\begin{array}{l}\text { Pregabalin I } 50 \mathrm{mg}(50) \text {, placebo (49), orally } \\
\text { I } 50 \mathrm{mg} \text { b.i.d. from I hour before surgery to } \\
4 \text { days after surgery }\end{array}$ & $\begin{array}{l}\text { VNS ( } 0 \text {, no pain; } 10, \text { worst, in the first } 4 \\
\text { postoperative days) }\end{array}$ \\
\hline Kim et al, $2017^{21}$ & $\begin{array}{l}\text { Single-center } \\
\text { RCT } \\
\text { double-blind }\end{array}$ & $\begin{array}{l}\text { Pregabalin I } 50 \mathrm{mg}(30) \text {, placebo (30), orally } \\
\text { I50 mg once I hour before surgery }\end{array}$ & $\begin{array}{l}\text { NRS (on arrival to the PACU and at postoperative } \\
6,24 \text {, and } 48 \text { hours) }\end{array}$ \\
\hline $\begin{array}{l}\text { Matsutani et al, } \\
2017^{22}\end{array}$ & $\begin{array}{l}\text { Single-center } \\
\text { RCT }\end{array}$ & $\begin{array}{l}\text { Pegabalin } 75 \mathrm{mg}(34) \text {, ropivacaine (34), orally } \\
75 \mathrm{mg} \text { b.i.d. from the day of surgery to } 5 \text { days } \\
\text { after surgery, } 0.3 \% \text { epidural ropivacaine } 5 \mathrm{~mL} \\
\text { intra-operatively, } 0.2 \% \text { epidural ropivacaine }+\mathrm{I} \\
\mu \mathrm{g} / \mathrm{mL} \text { fentanyl patient-controlled analgesia } 48 \\
\text { hours postsurgery }\end{array}$ & $\begin{array}{l}\text { NRS (on the morning of the first, third, and fifth } \\
\text { day after surgery) }\end{array}$ \\
\hline Metin et al, $2017^{23}$ & $\begin{array}{l}\text { Single-center } \\
\text { RCT }\end{array}$ & $\begin{array}{l}\text { Pregabalin } 300 \mathrm{mg}, 600 \mathrm{mg}+\text { vitamin } \mathrm{B}_{12} \mathrm{I} \mathrm{mg} \mathrm{(50),} \\
\text { diclofenac potassium } 50 \mathrm{mg}(50) \text {, orally } 300 \mathrm{mg} \\
+\mathrm{I} \mathrm{mg} \mathrm{qd} \mathrm{for} \mathrm{the} \mathrm{first} 7 \text { days, } 600 \mathrm{mg}+\mathrm{I} \mathrm{mg} \mathrm{qd} \\
\text { from } 7 \text { days to } 90 \text { days, orally } 50 \mathrm{mg} \text { for the first } \\
7 \text { days and then on demand }\end{array}$ & $\begin{array}{l}\text { VAS and LANSS (previous to the treatment day } 0 \\
\text { and on the } 15 \text { th, 30th, 60th, and 90th days) }\end{array}$ \\
\hline
\end{tabular}

Abbreviations: LANSS, the leads assessment of neuropathic symptoms and signs; NRS, numerical rating scale; VAS, visual analog scale; VNS, verbal numerical scale; PACU, post-anesthesia care unit.

results. And TSA indicated that the sample size in the metaanalysis did not reach the required sample size (Figure 6).

\section{Morphine consumption postoperatively}

Results describing postoperative morphine consumption were available from two studies $(n=160)$. Pregabalin was effective in reducing postoperative morphine consumption by -5.03 (95\% CI: -8.06 to $\left.-1.99 ; I^{2}=0 \% ; P=0.001\right)$. Sensitivity analysis did not significantly alter the summarized results, and TSA indicated that crossed its monitoring boundaries and reliable conclusions had been drawn (Figure 7).

\section{Side effects}

Six studies investigated the incidence of dizziness, and with pregabalin the incidence was higher $(\mathrm{n}=184 ; 95 \% \mathrm{CI}$ : $\left.1.36-8.17 ; P^{2}=0 \% ; P=0.009\right)$. The Egger test for publication 


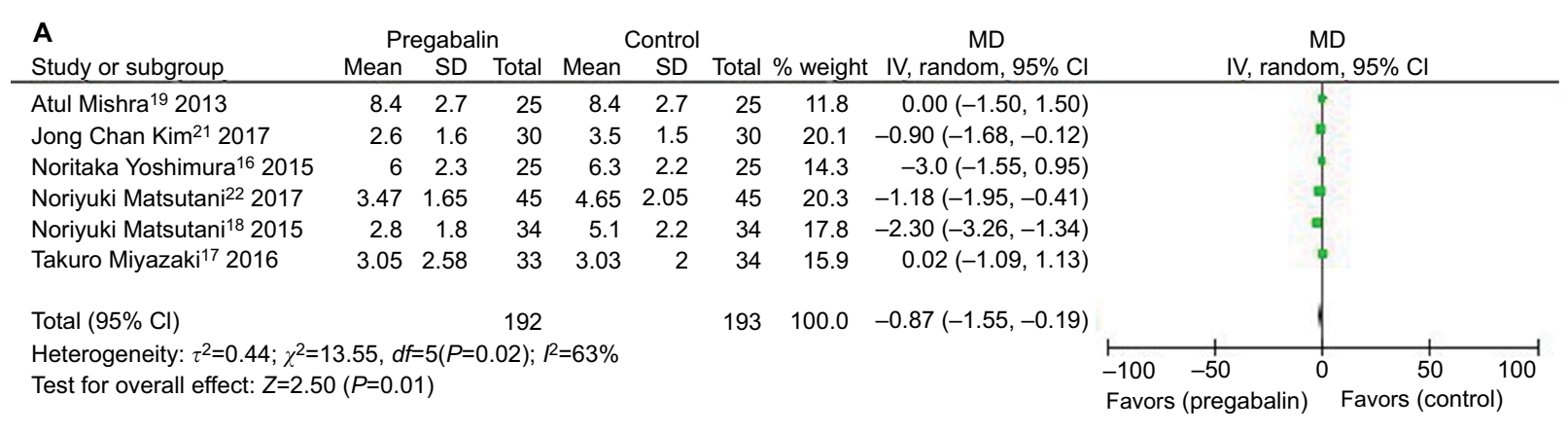

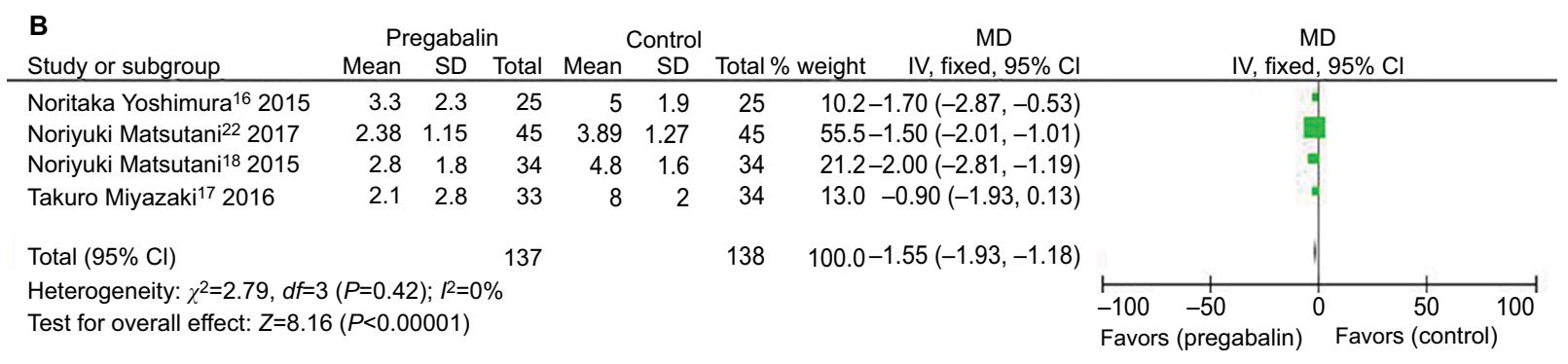

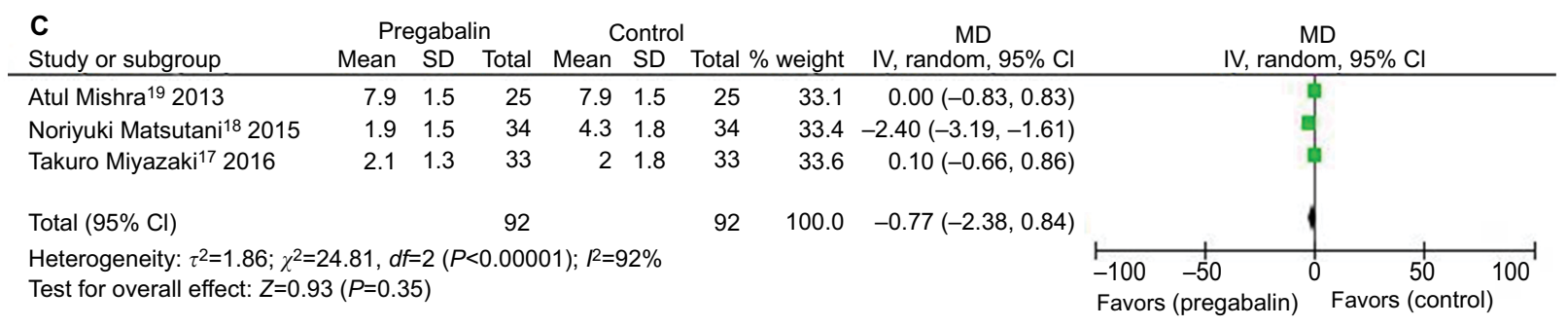

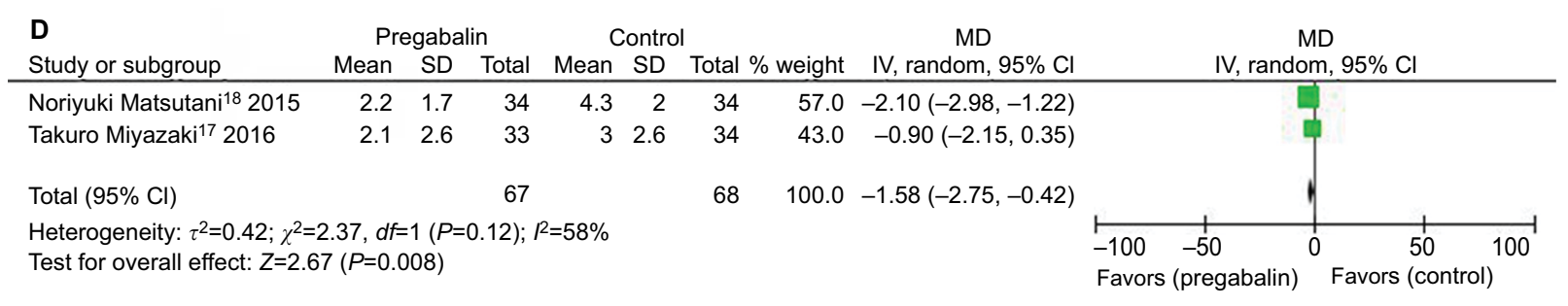

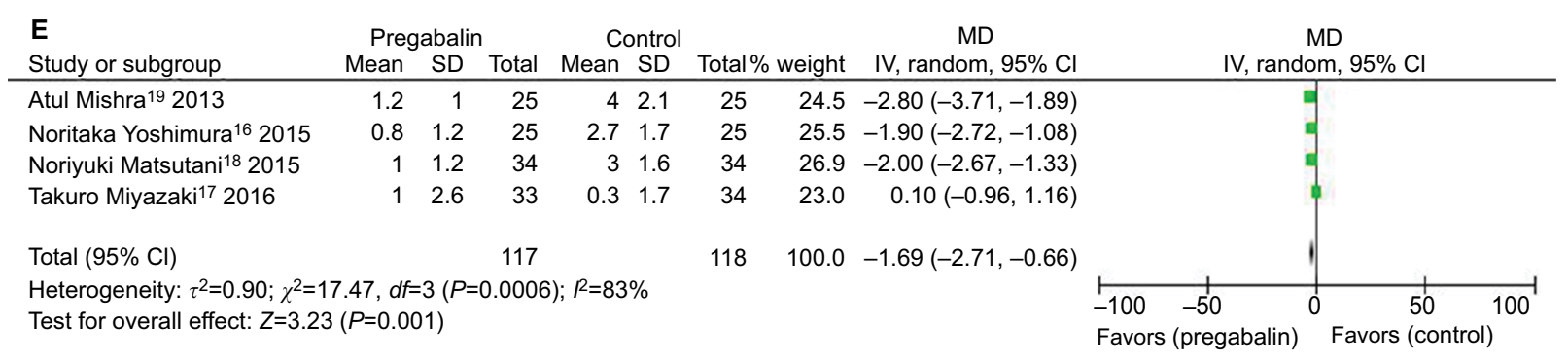

Figure 4 Forest plot of meta-analysis: postoperative pain intensity in patients receiving pregabalin.

Notes: (A) Postoperative I day. (B) Postoperative 3 days. (C) Postoperative 7 days. (D) Postoperative I month. (E) Postoperative 3 months.

Abbreviations: IV, inverse variance; MD, mean difference.

bias $(P=0.082)$. Four studies investigated the incidence of drowsiness, and with pregabalin the incidence was higher ( $\mathrm{n}=278 ; 95 \%$ CI: $\left.2.23-33.20 ; I^{2}=0 \% ; P=0.002\right)$. The Egger test for publication bias $(P=0.826)$. Three studies investigated the incidence of constipation, and with pregabalin the incidence was lower ( $\mathrm{n}=208 ; 95 \%$ CI: $0.09-0.59 ; P^{2}=0 \%$; $P=0.002)$. The Egger test for publication bias $(P=0.710)$. Six studies investigated the incidence of nausea and two studies investigated the incidence of vomiting. There was no statistically significant difference in nausea $(\mathrm{n}=500 ; 95 \% \mathrm{CI}$ : 
A

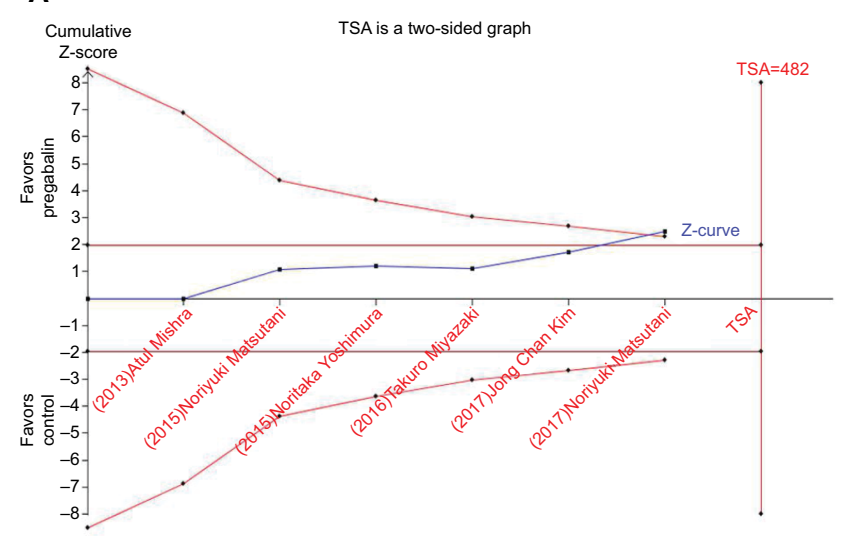

C

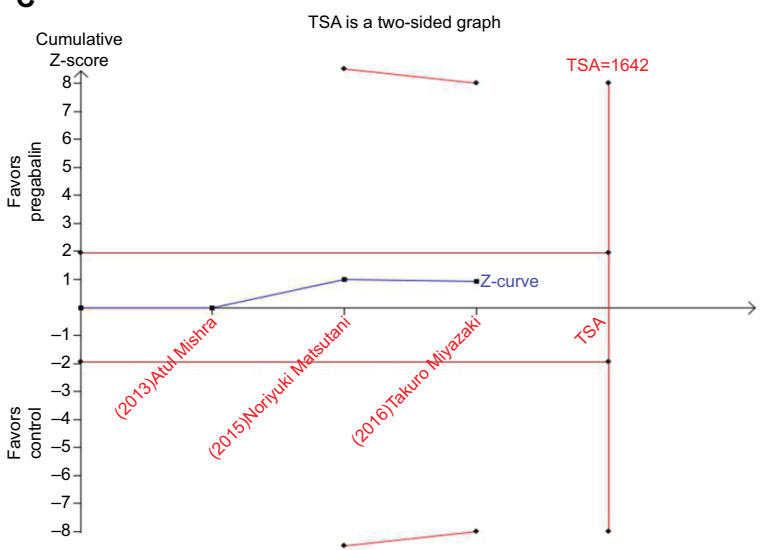

E

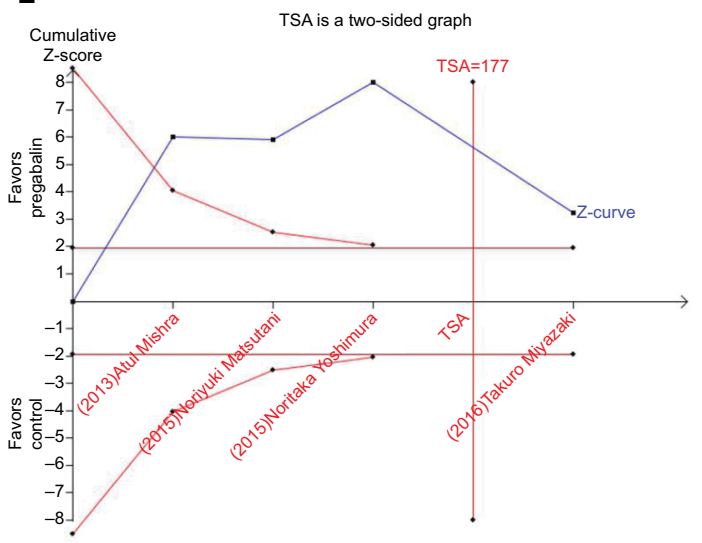

B

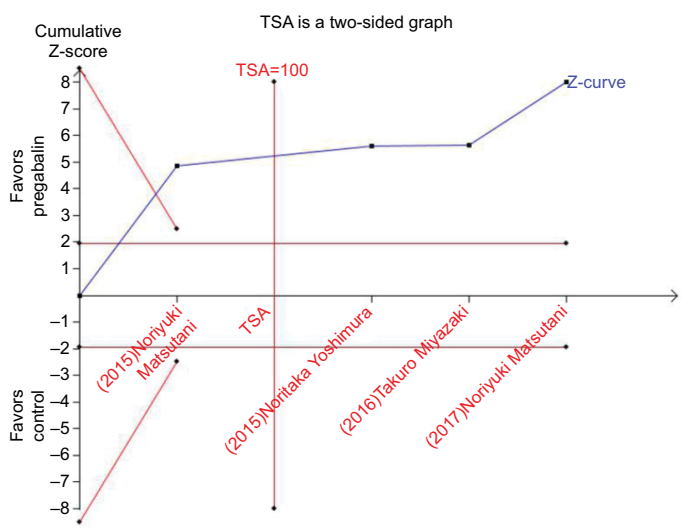

D

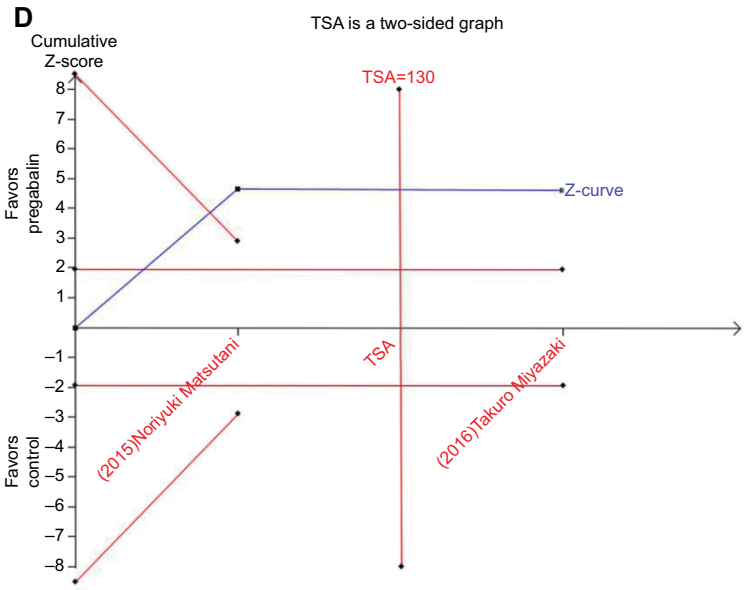

Figure 5 TSA: postoperative pain intensity in patients receiving pregabalin.

Notes: (A) Postoperative I day. (B) Postoperative 3 days. (C) Postoperative 7 days. (D) Postoperative I month. (E) Postoperative 3 months.

Abbreviation: TSA, trial sequential analysis.

$0.42-1.26 ; P^{2}=40 \% ; P=0.26$; the Egger test for publication bias, $P=0.867)$ and vomiting $(\mathrm{n}=200 ; 95 \% \mathrm{CI}: 0.36-1.90$; $I^{2}=0 \% ; P=0.65$; Figure 8 ). Sensitivity analysis did not significantly alter the summarized results. TSA indicated that the sample size in the meta-analysis did not reach the required sample size (Figure 9).

\section{Discussion}

This is the first meta-analysis to evaluate the analgesic efficacy of pregabalin as an adjuvant to a perioperative multimodal analgesic regimen in thoracotomy. After analyzing the combined results of 9 RCTs, we found that pregabalin significantly reduced pain scores on 1 and 3 days and 1 and 3 
A

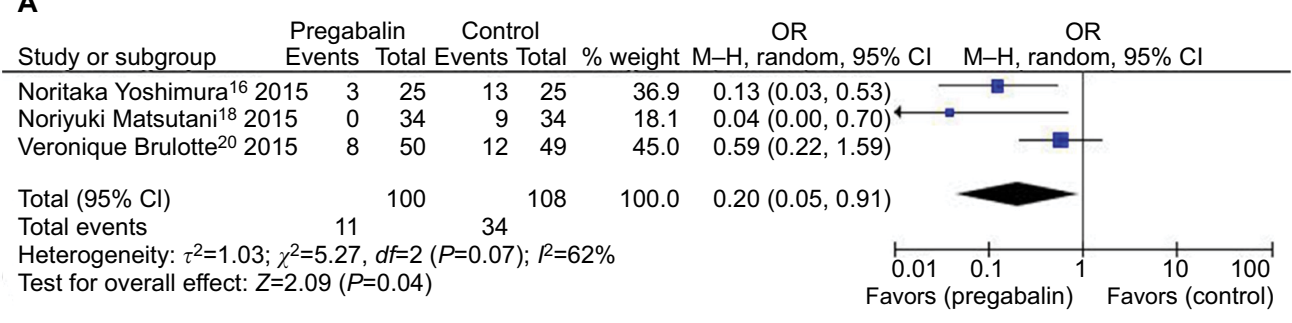

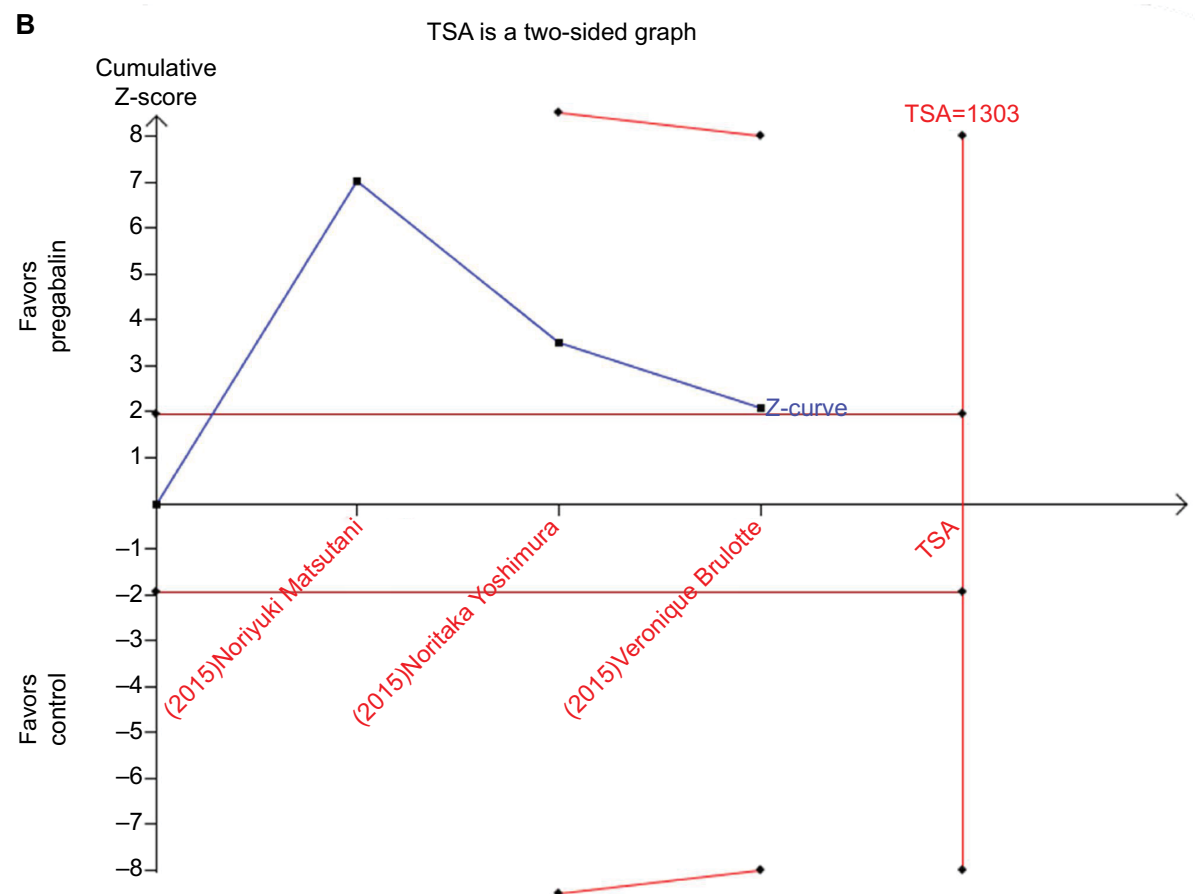

Figure 6 Forest plot of meta-analysis and TSA: postoperative neuropathic pain in patients receiving pregabalin.

Notes: (A) Forest plot of meta-analysis. (B) TSA.

Abbreviations: $\mathrm{M}-\mathrm{H}$, Mantel-Haenszel; TSA, trial sequential analysis.

months, reduced incidence of postoperative neuropathic pain, and reduced morphine consumption. However, the clinical significance of results may be limited by the heterogeneity in the included studies.

Our results are consistent with a meta-analysis that assess efficacy of pregabalin in acute postoperative pain under different surgical categories. ${ }^{24}$ The results showed that pregabalin reduced the pain score at rest 2 hours after surgery in the cardiothoracic procedure. But there was not a definite conclusion for persistent pain because of insufficient data. In other articles of meta-analysis, the efficacy of pregabalin in the specific surgical style of thoracotomy was not mentioned. The efficacy of perioperative pregabalin treatment for preventing chronic pain remains a matter of debate. In a recent meta-analysis of pregabalin, it especially evaluates the incidence of chronic postsurgical pain (CPSP) in 3, 6, and 12 months and the incidence of chronic postsurgical neuropathic pain at the same time point, including all published and unpublished articles. ${ }^{25}$ The conclusion is that the available data do not support with a moderate level of evidence for a systematic prevention of CPSP with pregabalin. Interestingly, it is shown that almost all of the overall effect comes from unpublished data being reverse of what one may expect and what has been published. None of unpublished trials reported pregabalin to be effective for preventing CPSP at any time (3, 6 , and 12 months). In our study, pregabalin made a reduction in pain scores in 1 and 3 months and the incidence of postsurgical neuropathic pain, and it may be attributed to our study 
A

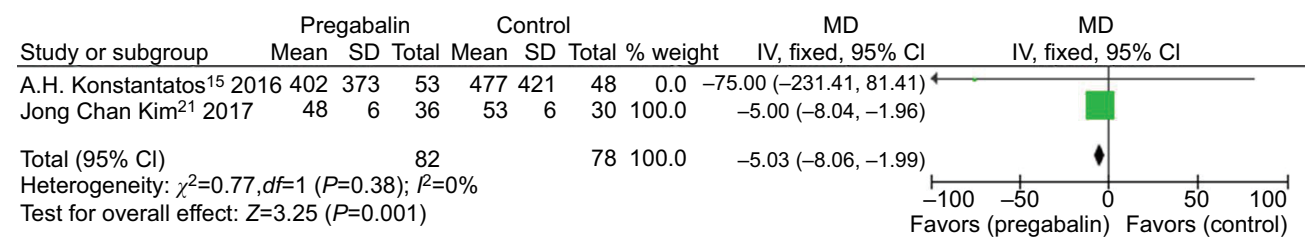

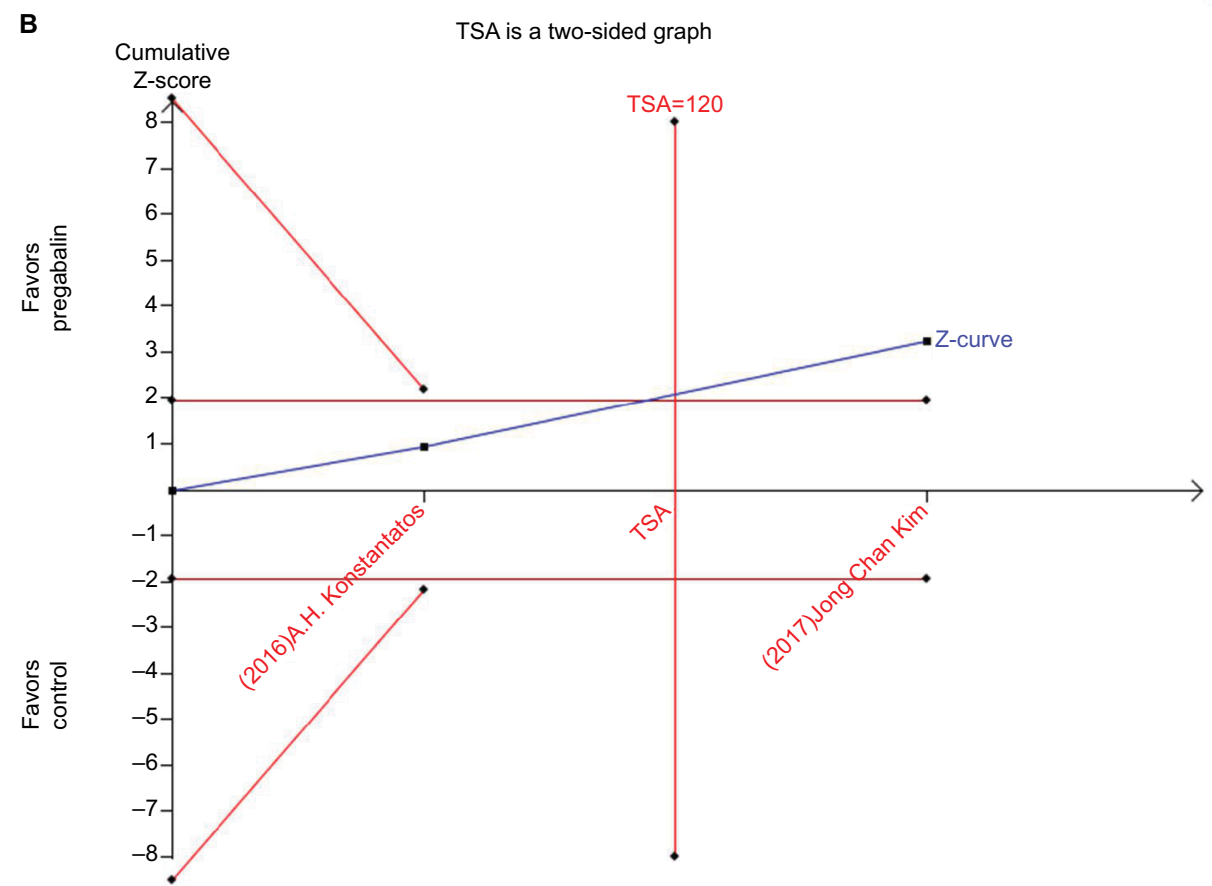

Figure 7 Forest plot of meta-analysis and TSA: postoperative morphine consumption in patients receiving pregabalin.

Notes: (A) Forest plot of meta-analysis. (B) TSA.

Abbreviations: IV, inverse variance; MD, mean difference; TSA, trial sequential analysis.

including all published articles under a single style surgery of thoracotomy. A higher incidence of chronic pain especially chronic neuropathic pain in the surgical style of thoracotomy, and pregabalin was used for chronic pain especially chronic neuropathic pain better than acute pain. It may be the reason why pregabalin is effective in thoracotomy. ${ }^{1,2}$ But the number of included articles was small. Therefore, more studies are needed to report the incidence of CPSP in thoracotomy, even when their results are not consistent with the earlier articles.

In addition, we found the morphine consumption was lower in the pregabalin group, although there were only two studies included. In a recent meta-analysis, it is shown that pregabalin may be a beneficial but small effect in postoperative pain management with minimal clinical relevant effect of morphine $5 \mathrm{mg}$ in 24 hours of opioid consumption, this result was consistent with us. ${ }^{26}$ We converted opioid use to morphine equivalents in studies because different opioid drugs and units were used to record opioid consumption. It was important to reduce opioid consumption because it has some side effects such as addiction, nausea, vomiting, constipation, and so on. In our study, there was a lower incidence of constipation, which may be the result of lower morphine consumption. ${ }^{27}$

We also found that there was a higher incidence of dizziness and drowsiness. Dizziness and drowsiness were most common adverse effects of pregabalin. Griffin reported that dizziness, fatigue, and somnolence were among the most common adverse effects of pregabalin. ${ }^{28}$ There was no significant difference of nausea and vomiting between the pregabalin group and the control group. In another study, postoperative administration of pregabalin has been shown to reduce nausea and vomiting for 


\section{A}

Study or subgroup

Pregabalin Control

$\mathrm{OR}$

OR

A.H. Konstantatos ${ }^{15} 2016$

Events Total Events

Total \%

$\begin{array}{rr}\text { weight } & \text { M-H, fixed, 95\% Cl } \\ 35.8 & 0.89(0.37,2.14) \\ 12.1 & 0.72(0.15,3.54) \\ 5.0 & 0.32(0.01,8.25) \\ 32.9 & 0.08(0.01,0.65) \\ 1.5 & 12.21(0.66,226.97) \\ 12.7 & 0.73(0.16,3.46) \\ 100.0 & 0.73(0.42,1.26)\end{array}$

Total $(95 \% \mathrm{Cl})$

$14 \quad 52$

$\begin{array}{rr}14 & 48 \\ 4 & 30\end{array}$

Jong Chan Kim²1 2017

Noritaka Yoshimura ${ }^{16} 2015$

Noriyuki Matsutani ${ }^{18} 2015$

Serda Kanbur Metin ${ }^{23} 2017$

Veronique Brulotte20 2015

$\begin{array}{ll}3 & 30 \\ 0 & 25\end{array}$

$\begin{array}{ll}0 & 25 \\ 1 & 45\end{array}$

$5 \quad 50$

125

$10 \quad 45$

450

252

33

Heterogeneity: $\chi^{2}=8.29, d f=5(P=0.14) ; R=40 \%$

Test for overall effect: $Z=1.13(P=0.26)$

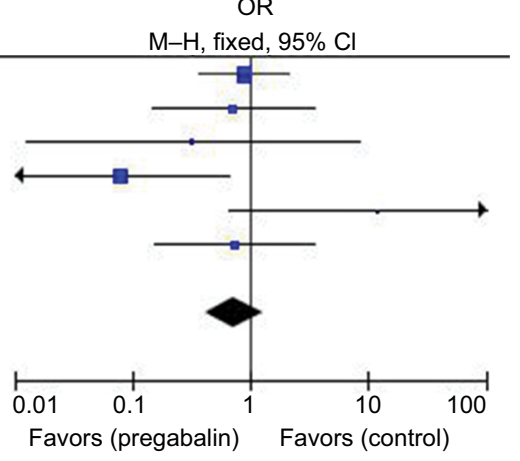

B

Pregabalin Control Events Total Events Total \% weight

OR

OR

Study or subgroup

$\begin{array}{lllll}14 & 52 & 14 & 48 & 87.8\end{array}$

$\mathrm{M}-\mathrm{H}$, fixed, $95 \% \mathrm{Cl}$

$\mathrm{M}-\mathrm{H}$, fixed, $95 \% \mathrm{Cl}$

A.H. Konstantatos ${ }^{15} 2016$

Veronique Brulotte 202015

$\begin{array}{lllll}14 & 52 & 14 & 48 & 87.8\end{array}$

$0.89(0.37,2.14)$

$0.33(0.01,8.21)$

Total $(95 \% \mathrm{Cl})$

102

$02 \quad 98 \quad 100.0$

Total events

14

Heterogeneity: $\chi^{2}=0.35, d f=1(P=0.55) ; R^{2}=0 \%$

Test for overall effect: $Z=0.45(P=0.65)$

15

$0.83(0.36,1.90)$

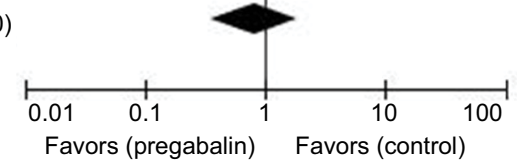

C

Study or subgroup

Pregabalin Control

OR

Jong Chan Kim ${ }^{21} 2017$ Events Total

Conts Tot

ixed,

d, $95 \% \mathrm{C}$

$\begin{array}{rr}\text { weight } & \mathrm{M}-\mathrm{H} \text {, fixed, } 95 \% \mathrm{Cl} \\ 16.1 & 1.00(0.06,16.76)\end{array}$

$17.00(0.90,320.37)$

Noritaka Yoshimura ${ }^{16} 2015$

Noriyuki Matsutani22 2017

Noriyuki Matsutani ${ }^{18} 2015$

Serda Kanbur Metin ${ }^{23} 2017$

Veronique Brulotte 202015

$\begin{array}{ll}1 & 30 \\ 6 & 25 \\ 3 & 45 \\ 3 & 34 \\ 3 & 50 \\ 3 & 50\end{array}$

30

$0 \quad 25$

6.3

46.7

$1.00(0.19,5.24)$

$\begin{array}{llll}1 & 34 & 15.2 & 3.19(0.32,32.36)\end{array}$

$\begin{array}{ll}1 & 34 \\ 0 & 50\end{array}$

$7.8 \quad 7.44(0.37,147.92)$

$7.9 \quad 7.29(0.37,145.03)$

Total $(95 \% \mathrm{Cl})$

234

$0 \quad 49$

Total events

19

$233 \quad 100.0$

$3.33(1.36,8.17)$

Heterogeneity: $\chi^{2}=4.45, d f=5(P=0.49) ; R=0 \%$

Test for overall effect: $Z=2.63(P=0.009)$

5

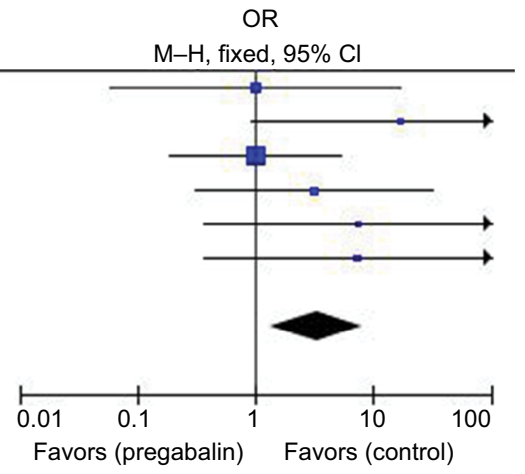

\section{D}

Pregabalin Control

Study or subgroup Events Total Events Total \% weight

OR

OR

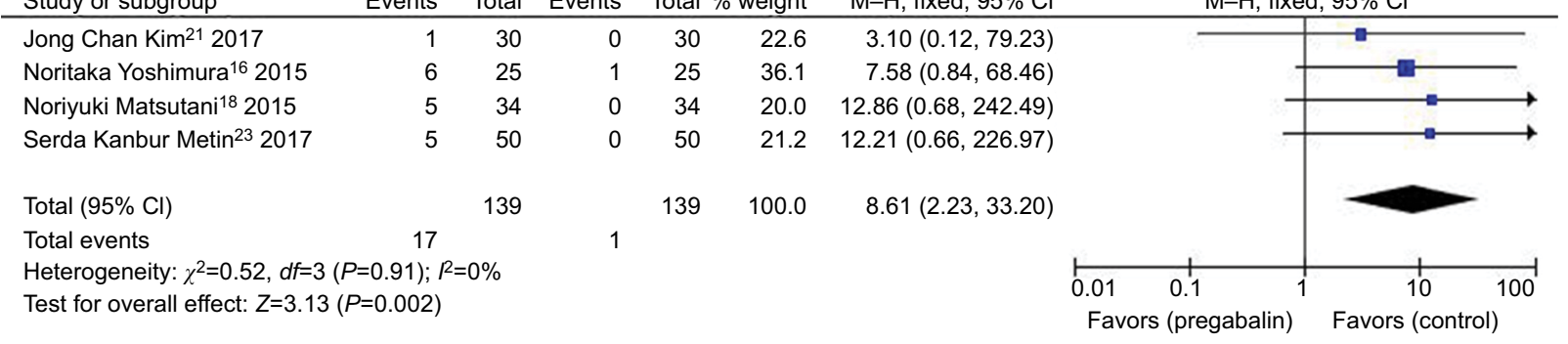

E

Pregabalin Control

OR

Study or subgroup Events Total

Control

Noritaka Yoshimura16 2015

Noriyuki Matsutani ${ }^{18} 2015$

$15 \quad 25$

Total \% weight $\mathrm{M}-\mathrm{H}$, fixed, $95 \% \mathrm{Cl}$ $0.29(0.08,1.09)$

$0.48(0.04,5.61)$

Noriyuki Matsutani22 2017

$\begin{array}{ll}1 & 34 \\ 2 & 45\end{array}$

2134

40.3

9.3

$0.14(0.03,0.69)$

Total $(95 \% \mathrm{Cl})$

104

Total events

18

$104 \quad 100.0$

$0.23(0.09,0.59)$

Heterogeneity: $\chi^{2}=0.80, d f=2(P=0.67) ; R=0 \%$

34

Test for overall effect: $Z=3.08(P=0.002)$

Figure 8 Forest plot of meta-analysis: adverse effects in patients receiving pregabalin.

Notes: (A) Nausea. (B) Vomiting. (C) Dizziness. (D) Drowsiness. (E) Constipation.

Abbreviation: $\mathrm{M}-\mathrm{H}$, Mantel-Haenszel. 
A

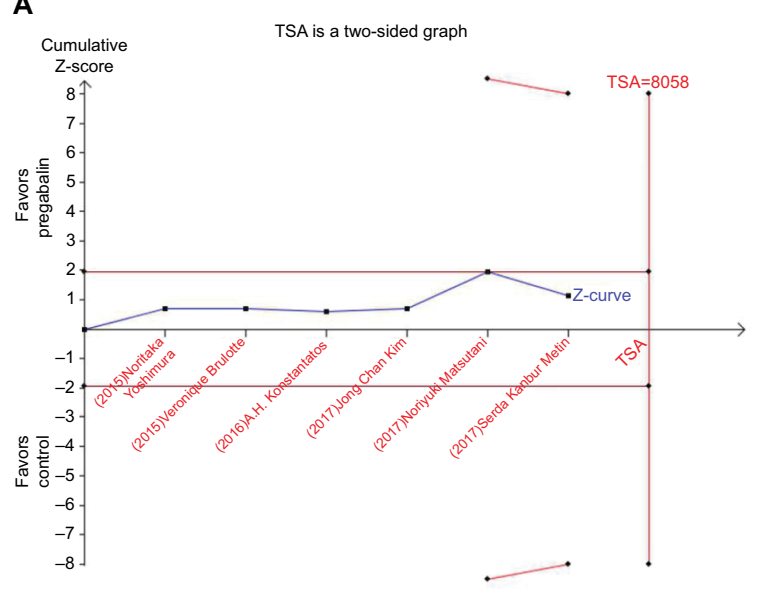

C

Cumulative

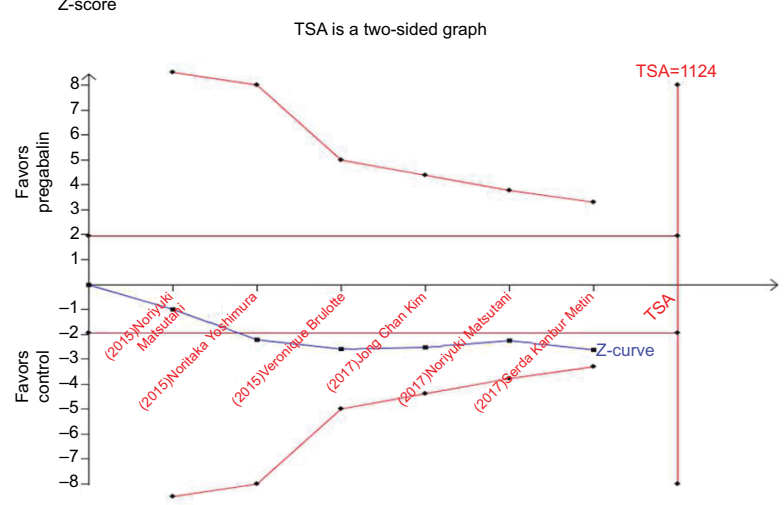

E

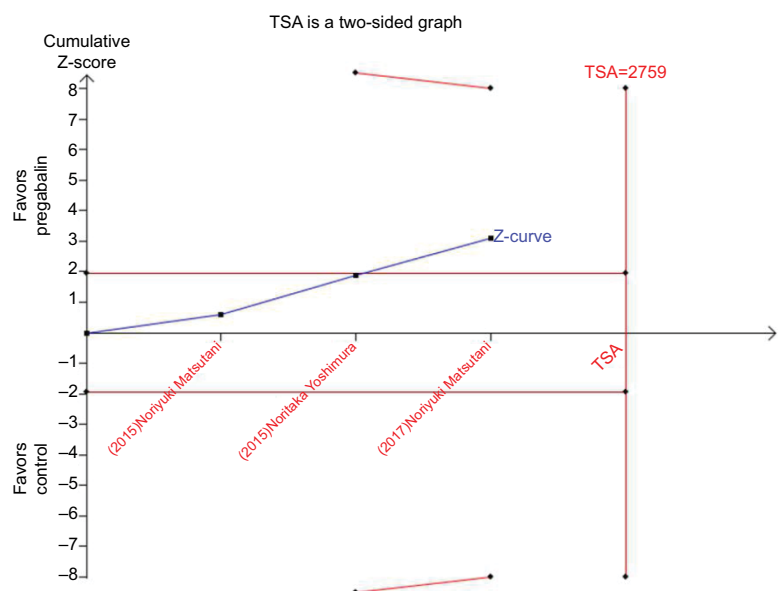

B

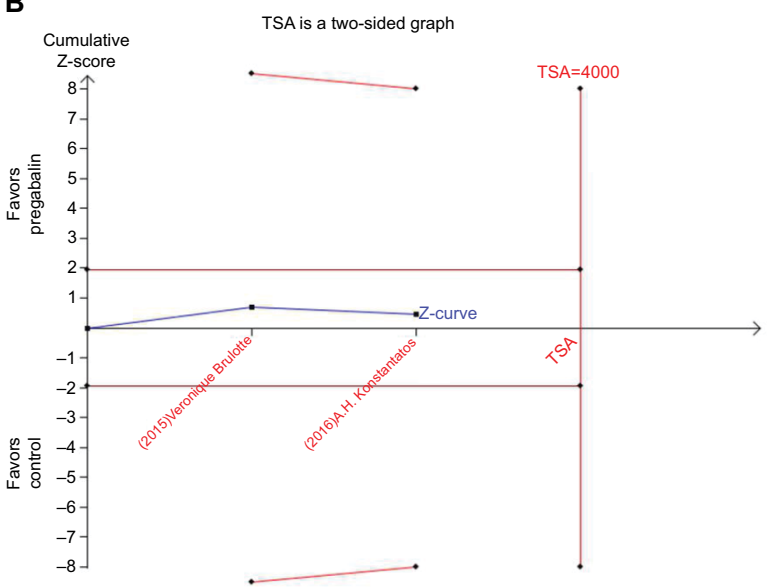

D

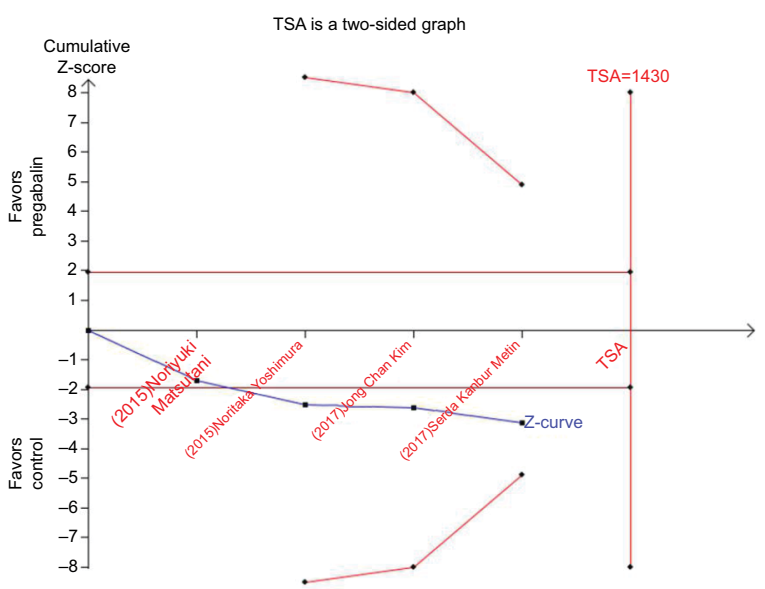

Figure 9 TSA: adverse effects in patients receiving pregabalin.

Notes: (A) Nausea. (B) Vomiting. (C) Dizziness. (D) Drowsiness. (E) Constipation. Abbreviation: TSA, trial sequential analysis.

the reason of reduction in opioid consumption. ${ }^{29,30}$ In our study, the phenomenon that pregabalin did not reduce nausea and vomiting may result from the additional analgesic drugs with nonopioids instead of opioids drugs in most included studies.

This meta-analysis has several limitations that should be considered. First, the standard trials were limited, and the sample size was relatively insufficient, these factors could make the power test insufficient. Second, differences existed among trials, such as the doses of administration and outcome indicators of included RCTs. These factors may affect the meta-analysis and conclusion. Therefore, more high-quality studies are needed to reduce the effect of bias on study results. 


\section{Conclusion}

In conclusion, our meta-analysis indicated that pregabalin could improve acute and chronic pain control, and reduce opioids consumption. However, future studies regarding doses and pregabalin medication are required.

\section{Acknowledgments}

This study was supported by The Medical Science Research Foundation of Zhejiang Province (2019314366), The Natural Science Fund of Zhejiang Province (LY17H090011) and The Science and Technology Department of Zhejiang Province Public Welfare Project (2016C33G2010165).

\section{Disclosure}

The authors report no conflicts of interest in this work.

\section{References}

1. Bayman EO, Parekh KR, Keech J, Selte A, Brennan TJ. A prospective study of chronic pain after thoracic surgery. Anesthesiology. 2017;126(5):938-951.

2. Homma T, Doki Y, Yamamoto Y, et al. Risk factors of neuropathic pain after thoracic surgery. J Thorac Dis. 2018;10(5):2898-2907.

3. Joshi GP, Bonnet F, Shah R, et al. A systematic review of randomized trials evaluating regional techniques for postthoracotomy analgesia. Anesth Analg. 2008;107(3):1026-1040.

4. Kehlet H, Dahl JB. The value of "multimodal" or "balanced analgesia" in postoperative pain treatment. Anesth Analg. 1993;77(5):1048-1056.

5. Yekkirala AS, Roberson DP, Bean BP. Breaking barriers to novel analgesic drug development. Anesthesiology. 2017;16(11):810.

6. Li Z, Taylor CP, Weber M, et al. Pregabalin is a potent and selective ligand for $\alpha(2) \delta-1$ and $\alpha(2) \delta-2$ calcium channel subunits. Eur J Pharmacol. 2011;667(1-3):80-90.

7. Gray P. Pregabalin in the management of central neuropathic pain. Expert Opin Pharmacother. 2007;8(17):3035-3041.

8. Higgins J, Green S. Guide to the contents of a Cochrane protocol and review. In: Cochrane Handbook for Systematic Reviews of Interventions version 5.1.0. Chapter 4. The Cochrane Collaboration; 2011. Available from: http://www.cochrane-handbook.org. Accessed December 1, 2016.

9. Liberati A, Altman DG, Tetzlaff J, et al. The PRISMA statement for reporting systematic reviews and meta-analyses of studies that evaluate healthcare interventions: explanation and elaboration. BMJ. 2009;339(7):b2700.

10. Easterbrook PJ, Berlin JA, Gopalan R, Matthews DR. Publication bias in clinical research. Lancet. 1991;337(8746):867-872.

11. Brogi E, Kazan R, Cyr S, Giunta F, Hemmerling TM. Transversus abdominal plane block for postoperative analgesia: a systematic review and meta-analysis of randomized-controlled trials. Can J Anaesth. 2016;63(10):1184-1196.

12. Pereira J, Lawlor P, Vigano A, Dorgan M, Bruera E. Equianalgesic dose ratios for opioids. a critical review and proposals for long-term dosing. J Pain Symptom Manage. 2001;22(2):672-687.

\section{Journal of Pain Research}

\section{Publish your work in this journal}

The Journal of Pain Research is an international, peer reviewed, open access, online journal that welcomes laboratory and clinical findings in the fields of pain research and the prevention and management of pain. Original research, reviews, symposium reports, hypothesis formation and commentaries are all considered for publication.
13. Higgins JP, Thompson SG. Quantifying heterogeneity in a meta-analysis. Stat Med. 2002;21(11):1539-1558.

14. Thorlund K, Engstrøm J, Wetterslev J, Brok J, Imberger G, Gluud C. User Manual for Trial Sequential Analysis (TSA). Copenhagen, Denmark: Copenhagen Trial Unit, Centre for Clinical Intervention Research; 2011;1-115.

15. Konstantatos AH, Howard W, Story D, Mok LY, Boyd D, Chan MT. A randomised controlled trial of peri-operative pregabalin vs. placebo for video-assisted thoracoscopic surgery. Anaesthesia. 2016;71(2):192-197.

16. Yoshimura N, Iida H, Takenaka M, et al. Effect of postoperative administration of pregabalin for post-thoracotomy pain: a randomized study. J Cardiothorac Vasc Anesth. 2015;29(6):1567-1572.

17. Miyazaki T, Sakai T, Sato $S$, et al. Is early postoperative administration of pregabalin beneficial for patients with lung cancer? Randomized control trial. J Thorac Dis. 2016;8(12):3572-3579.

18. Matsutani N, Dejima H, Takahashi Y, Kawamura M. Pregabalin reduces post-surgical pain after thoracotomy: a prospective, randomized, controlled trial. Surg Today. 2015;45(11):1411-1416.

19. Mishra A, Nar AS, Bawa A, Kaur G, Bawa S, Mishra S. Pregabalin in chronic post-thoracotomy pain. J Clin Diagn Res. 2013;7(8): 1659-1661.

20. Brulotte V, Ruel MM, Lafontaine E, Chouinard P, Girard F. Impact of pregabalin on the occurrence of postthoracotomy pain syndrome: a randomized trial. Reg Anesth Pain Med. 2015;40(3):262-269.

21. Kim JC, Byun S, Kim S, et al. Effect of preoperative pregabalin as an adjunct to a multimodal analgesic regimen in video-assisted thoracoscopic surgery: a randomized controlled trial. Medicine. 2017;96(49):e8644.

22. Matsutani N, Dejima H, Nakayama T, et al. Impact of pregabalin on early phase post-thoracotomy pain compared with epidural analgesia. J Thorac Dis. 2017;9(10):3766-3773.

23. Metin SK, Meydan B, Evman S, Dogruyol T, Baysungur V. The effect of pregabalin and methylcobalamin combination on the chronic postthoracotomy pain syndrome. Ann Thorac Surg. 2017;103(4): 1109-1113.

24. Lam DM, Choi SW, Wong SS, Irwin MG, Cheung CW. Efficacy of pregabalin in acute postoperative pain under different surgical categories: a meta-analysis. Medicine. 2015;94(46):e1944.

25. Martinez V, Pichard X, Fletcher D. Perioperative pregabalin administration does not prevent chronic postoperative pain: systematic review with a meta-analysis of randomized trials. Pain. 2017;158(5):775-783.

26. Fabritius ML, Strøm C, Koyuncu S, et al. Benefit and harm of pregabalin in acute pain treatment: a systematic review with meta-analyses and trial sequential analyses. Br J Anaesth. 2017;119(4):775-791.

27. Nalamachu S, Gudin J, Datto C, et al. Efficacy and safety of naloxegol for opioid-induced constipation assessed by specific opioid medication, opioid dose, and duration of opioid use. J Opioid Manag. 2018;14(3):211-221.

28. Griffin E, Brown JN. Pregabalin for the treatment of restless legs syndrome. Ann Pharmacother. 2016;50(7):586-591.

29. Li F, Ma J, Kuang M, et al. The efficacy of pregabalin for the management of postoperative pain in primary total knee and hip arthroplasty: a meta-analysis. J Orthop Surg Res. 2017;12(1):49.

30. Sawan H, Chen AF, Viscusi ER, Parvizi J, Hozack WJ. Pregabalin reduces opioid consumption and improves outcome in chronic pain patients undergoing total knee arthroplasty. Phys Sportsmed. 2014;42(2): $10-18$.

\section{Dovepress}

The manuscript management system is completely online and includes a very quick and fair peer-review system, which is all easy to use. Visit http://www.dovepress.com/testimonials.php to read real quotes from published authors. 